\title{
MATHEMATICS AS POTENTIAL FOR THE PERSON'S RESILIENCE
}

\author{
Evija KOPEIKA, Institute/department of Engineering Mathematics, Faculty of Computer Science and Information \\ Technology, Riga Technical University, Daugavgrīvas sreet 2- 146, Riga, Latvia; evija.kopeika@,rty.lv
}

\begin{abstract}
Scientific literature offers extensive examples of the role of mathematics education in the development of personality and intelligence as well as its application in everyday life and professional activities. Furthermore, the attitude towards the role of mathematical knowledge in the labour market is widely discussed in the society. In order to reflect the views of respondents on the issues of mathematics education and the potential values of mathematics, the survey was carried out. The research data was analysed considering the respondents` education speciality, gender, age and mathematics learning experience. Study results show that mathematics is widely used in everyday life as well as in professional activities, and gives advantage in the labour market. It is difficult to learn mathematics but it is highly worthy. Thus the subject of mathematics is becoming a crucial instrument for promoting an all-round education and personal development. Therefore, many higher education courses have to be mathematics-intensive, and students need to have a high level of competence in the subject to promote person's resilience.
\end{abstract}

Keywords: mathematics, mathematical competence, person's resilience

\section{INTRODUCTION}

For centuries it has been believed that mathematics is a field a good knowledge of which is crucial for an individual's successful self-development and career. The importance of mathematics subject can be seen not only in the sciences but also in several undergraduate courses, for example, in engineering, psychology, sciences and social sciences (Norris, 2012). Some scientists have even argued that mathematics, and in particular statistics, is significant even for non STEM subjects at university (Porkess, 2012). It has been stressed in the recent years in various business and governmental seminars and conferences, as well as in a sufficient amount of reports. Numerous explanations have been given why mathematics is important. Therefore, it is essential to prepare young people starting from school and afterwards at university to have a good knowledge of mathematics, to be able not only solve classical tasks, but also more complex ones, to see mathematical problems in various situations of life and solve them. Some scientists have said that in contemporary world of "rapid change" (ACME, 2011, pp. 1), especially technological change, the demand for mathematical skills is increasing (Burghes, 2011; Norris, 2012; Vorderman et al, 2011).

To find out the opinion and experience of the entrants of the universities in Latvia about usefulness of acquired mathematics knowledge a study was carried out in the spring of 2017 in two of the biggest universities in Latvia - the Riga Technical University (further RTU) and the Latvia University of Agriculture (further LUA). Respondents were asked whether mathematics had been useful during the studies of professional subjects, in everyday life, and starting their careers. Three diagnostic units were enclosed in the study: the role of mathematics in everyday life; in professional activities, connected with the labour market, and mathematics in the general human development. Respondents had to evaluate given statements, expressing approval or rejection using four degrees from the Likert scale: strongly agree, agree, disagree, strongly disagree.

591 respondent took part in the study. Since the questionnaires were completed in a good quality, without leaving any empty spaces in the answer fields for the questions relevant to this study, all the evaluations have been taken into consideration during the estimation. Results of the analysis discussed in this article have been evaluated from three points of view - respondents altogether, results compared between the universities and between the chosen clusters of specialties. The object of the study - the role of mathematics in solving different problems and in extending career opportunities. The aim of the study - by using the results of the questionnaire to carry out the comparative analysis of the data and find out how according to students`opinion mathematics affects various processes of human development.

\section{RESEARCH METHODS}

A student questionnaire about the knowledge and skills of mathematics, their role in a person's life and professional development was carried out in the spring of 2017 in two of the biggest universities in Latvia. 
Results of the questionnaire, in which 591 respondent took part ( the electronic questionnaire form is available on http://www.iipc.lv/surv/index.php/393736/lang-lv) were used in the study.

Table 1 Characteristics of the questionnaire samplings of students

\begin{tabular}{|l|c|c|c|}
\hline & RTU\% & LUA\% & TOTAL\% \\
\hline Respondents & $73 \%$ & $27 \%$ & $100 \%$ \\
\hline Full answers & $84 \%$ & $78 \%$ & $82 \%$ \\
\hline
\end{tabular}

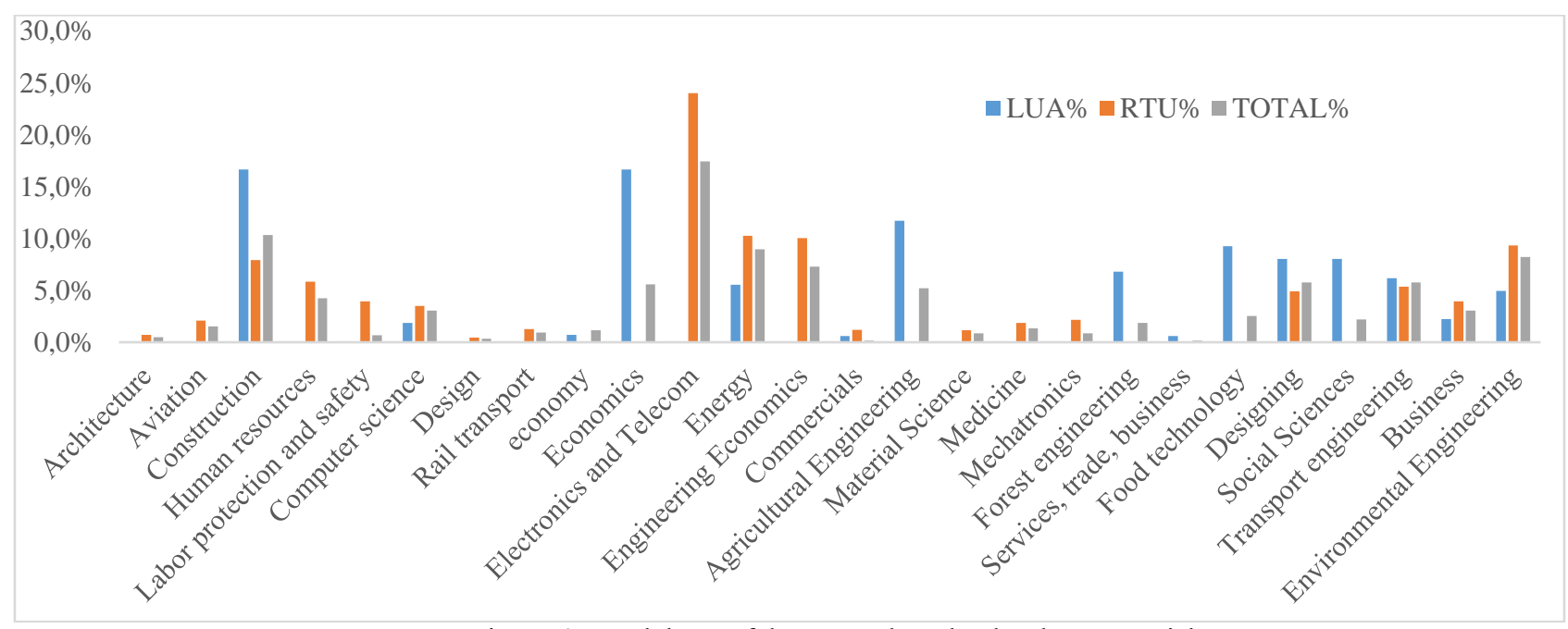

Picture 1. Breakdown of the respondents by the chosen specialty.

At first glance at Table 1, it might seem that the number of the entrants from both universities is not proportional, however, the amount of the sampling in each institution has been chosen by the principle of regularity, taking into consideration that in 2016 there were 14997 entrants in RTU, but in LUA - 4353 (which is $29 \%$ of amount of students in RTU).

Since the range of represented specialties was quite wide (see Picture 1), and most of represented fields did not exceed $2 \%$, respondents were grouped into eight clusters using both clustering method and subjective indicators (see Table 2 ).

Table 2 Distribution of respondents into specialty clusters

\begin{tabular}{|c|c|c|c|}
\hline . & LUA & RTU & TOTAL \\
\hline Electronics, Energy & $5 \%$ & $34 \%$ & $26 \%$ \\
\hline Civil Engineering & $23 \%$ & $15 \%$ & $18 \%$ \\
\hline Transport & $11 \%$ & $10 \%$ & $11 \%$ \\
\hline Human Resources, Social Sphere & $8 \%$ & $10 \%$ & $9 \%$ \\
\hline Economics & $19 \%$ & $14 \%$ & $16 \%$ \\
\hline Agricultural engineer & $22 \%$ & $9 \%$ & $13 \%$ \\
\hline Computer science & $3 \%$ & $7 \%$ & $6 \%$ \\
\hline Food technology & $9 \%$ & $0 \%$ & $3 \%$ \\
\hline
\end{tabular}

In the analysis of the data such methods have been used: descriptive method, method of analysis and synthesis, also Crosstabs tabulation method was often used in the research, and the cluster analysis was carried out.

\section{ANALYSIS OF THE RESULTS AND THE DISCUSSION}

For hundreds of years bright minds of humanity have thought that "mathematics is a science whose subject matter is special forms and quantitative relationships of the real world" (Angels in Fatima, 2012, pp.2). Nowadays its application scope and ability to improve the quality of life has only grown.

Doctor Roohi Fatima has stated: „Mathematics has been successfully used in the development of science and technology in 20th - 21st century. The areas like advanced semi-conductor devices, bio-technology, digital image technology, Nano-technology, artificial satellites, and rockets all are based on mathematical concepts. The recent success of NASA's Mars Rover is also based on mathematics" (Fatima, 2012, pp. 14). The viewpoint of the American professor Julie Gainsburg coincides with the previous statement: "Mathematics is the key to opportunity. No longer just the language of science, mathematics now contributes in direct and fundamental ways to business, finance, health, and defence. For students, it opens doors to careers. For citizens, it enables informed decisions. For nations, it provides the knowledge to compete in a technological community" (Julie Gainsburg, 2005, pp. 15). Despite the aforementioned significant role of mathematics in our lives, mathematics knowledge of pupils and students` is deteriorating year by year. Outside of school, in everyday life and work, both employers and customers complain about employees whose mathematics knowledge is low, for example, there is a price given in the shop with a relative discount, and the sales person cannot calculate the accurate price for the client. When doing the data gathering and analyses for a company, an employee makes some 
operations on a computer, gets the figures which are ordered in tables and hands them in, but he or she does not go into them and check whether carried out mathematical actions are correct and that no mistakes have occurred during the work. Critics suggest that these problems appear because of the stereotypical conception of mathematics and the lack of competences. In addition, international evaluations indicate that already after finishing primary education, pupils do not reach the expected levels of mathematic knowledge and competences.

Therefore, it is important to evaluate not only pupils' marks, but also asses their thoughts and understanding of how acquired mathematical knowledge might help them in the future career.

To evaluate students ' level of mathematical knowledge the author of the study went beyond the registered pupils' results in the subject of higher mathematics and its subsidiaries - in electrical sciences/ mechanical engineering. She tried to clarify to what extent entrants use their mathematics skills to prepare themselves for the labour market and to acquire the subjects of their specialties - in engineering sciences, economics, and in other specialty groups. The means for this were questionnaires which were sent to all of the students of RTU and LUA (both full time and part time).

One block of questions included in the questionnaire was: "What, in your opinion, are the potential values of mathematics?" with possible directions for thinking:

1. Mathematical thinking helps solving life and professional problems;

2. People who understand mathematics will easily deal with tasks that require thinking;

3. People who know mathematics well gain higher evaluation from the employers.

With possible answers: strongly agree, agree, disagree, strongly disagree, do not know.

As the answers of students from RTU and LUA were similar to the first two sets, they will not be analysed separately.

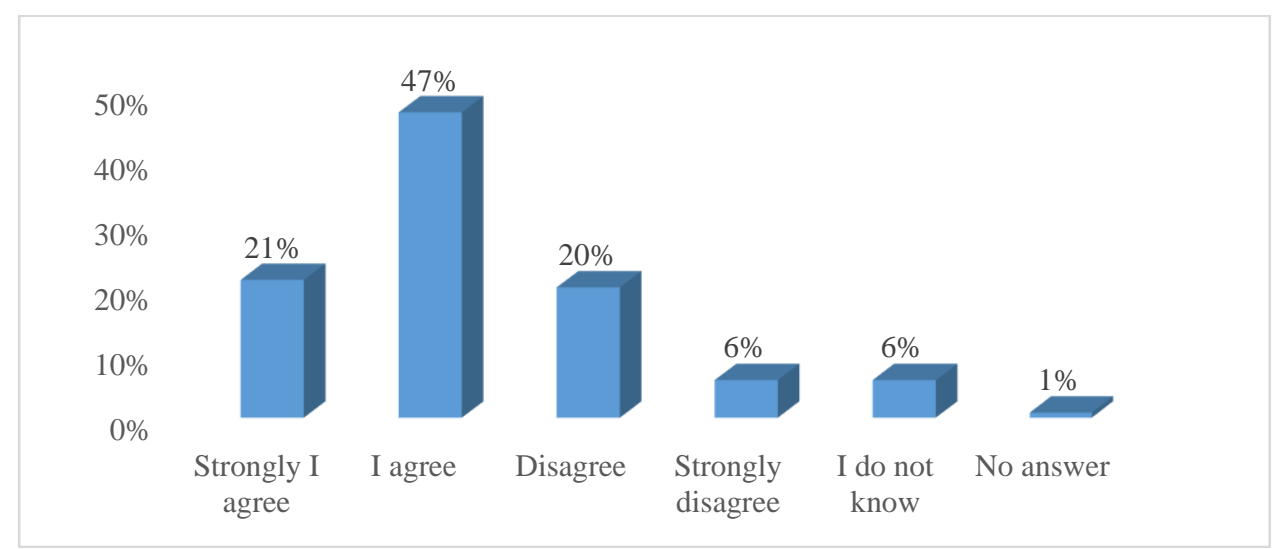

Picture 2. Mathematical thinking helps solving life and professional problems

As it can be seen in Picture 2 students' opinions on the role of the mathematics in solving life and professional problems differ. Although, on average $56 \%$ of respondents agree or even strongly agree to this statement, $44 \%$ of them have the opposite opinion. This situation is depicted in the given answers by specialty clusters (see Picture 3 ).



Picture 3. Mathematical thinking helps solving life and professional problems in ratings of students of different specialty clusters

When comparing specialty clusters, for respondents who study computer sciences and information technologies the role of mathematical thinking in solving various problems had the lowest evaluation (this idea is supported by only $33 \%$ ). From the explanatory answers of the respondents it is possible to distinguish that part of the young people enjoy 
the new technologies, they do the research on various applications and thus become confident that fundamental sciences (including mathematical understanding) which used to help solving different problems, now are outdated. According to them nowadays it can be done by using other tools that do not require great mental effort.

However, according to Finnish professor Kirsi Silius and her fellow researchers (Silius et al, 2011) it has been observed that in recent decades the mathematical skills of students entering university have deteriorated in Western Countries. It is sometimes argued that with the creation of computers people do not need so thorough ability to do mathematics. In ACME (2011) we find the statement that shows absolutely opposite situation: "Off-the-shelf and purpose-designed computer software packages are creating ever more data sets, statistics and graphs. Working with mathematical models, which people need to be able to understand, interpret, interrogate and use advantageously, is becoming commonplace. The use of quantitative data is now omnipresent and informs workplace practice." (ACME, 2011)

Whereas, the highest evaluation was given by food technologists $(80 \%)$ and from specialists of human resources and social fields (72\%). Representatives of these fields pointed out that good knowledge of mathematics and mathematical thinking is largely connected to the ability quickly and precisely calculate proportions, percentage and various types of arithmetic activities when working with financial resources and tangible goods.

Some answers reflect a positive feedback - a great part of the respondents have pointed out that an ability to acknowledge functional coincidences and their characteristics between different factors, to analyse them, and on a ground of results, carry out planning and forecasting, is directly derived from a hard work during the lessons of mathematics at school and later also at university. They applied this knowledge both while studying the professional subjects of their specialties and also working parallel to studies. The given answers were also closely connected to the next question: "What, in your opinion, are the potential values of mathematics?" [A person who understands mathematics will easily deal with tasks that require thinking].

Analysing the answers about the potential value of mathematics in the connection with the work that requires thinking, capacity of time and work done (see Picture 4), one can see that $68 \%$ of total respondents agree to the given statement.

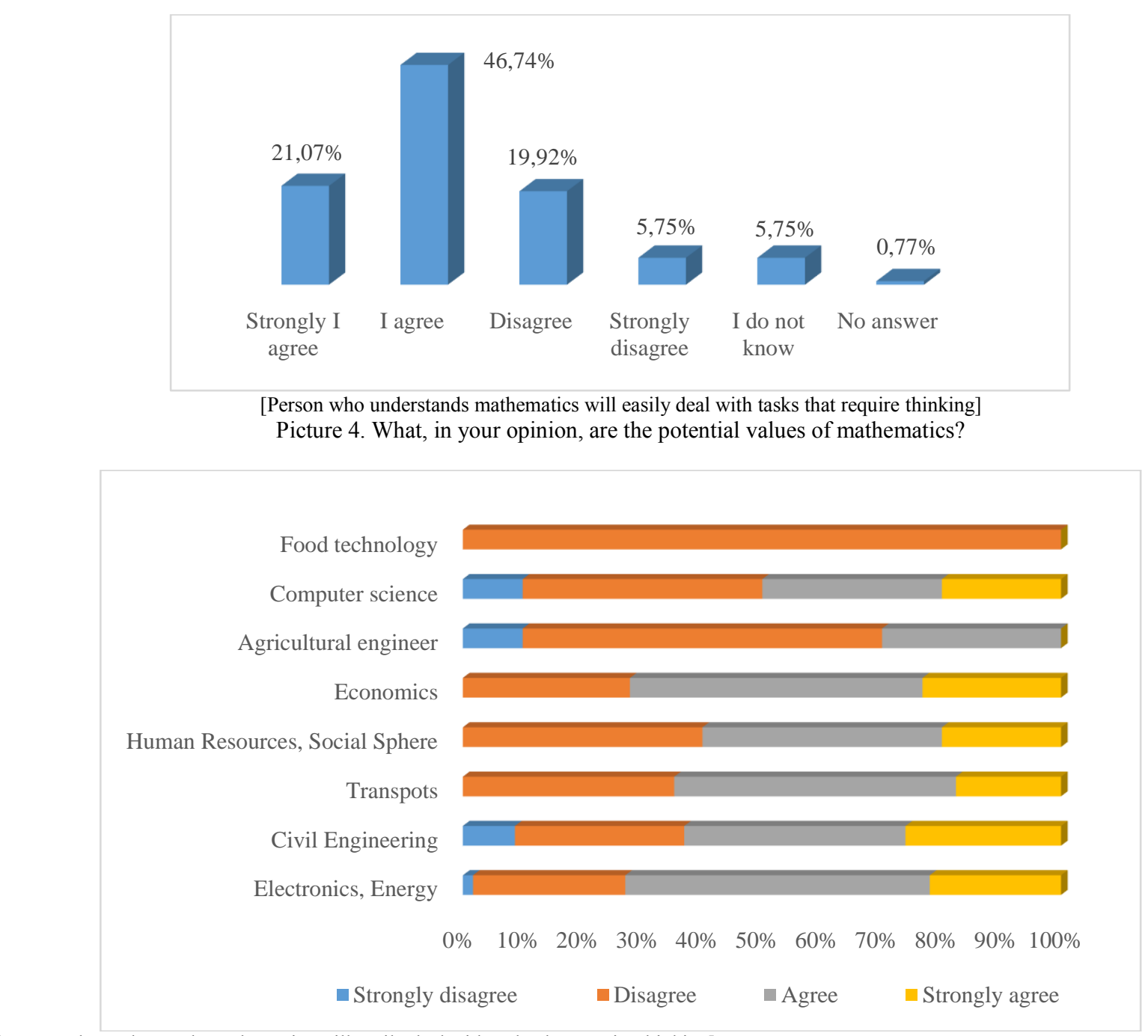

[Person who understands mathematics will easily deal with tasks that require thinking]

Picture 5. What, in your opinion, are the potential values of mathematics?

Among all clusters of specialities, the greatest supporters of the statement (it is easier for the people who understand mathematics to deal with works that require thinking) are students of electronics and energy (73\%), of 
economic sciences (72\%), transport (65\%), engineering (63\%), and the representatives of social sciences (60\%), who mainly chose answers I strongly agree and agree. As an explanation, respondents of electronics and energy pointed out that, for example, theoretical ground of electronics and even the simplest planning and laboratory works or electronic chains are impossible to be done or the essence, characteristics and possible reactions to be understood without sufficient knowledge of mathematics not only at school level, but also the higher mathematics, especially, line integrals, the field theory and functions of complex variables. Similar explanations were also given by representatives of other specialties.

Students are the future employees and employers, therefore, it is crucial they would be able to evaluate their skills and possibilities so when they start career they would be successful and convincing. One of the factors that most certainly must be taken into consideration is the opinion of the employers on how qualified employees they expect to work in their company, furthermore, who they do not want to hire. One of the skills that gains attention is employees ' mathematical knowledge and ability to use it in everyday life and work process. Published results of several studies show that in the Baltic states $66 \%-91 \%$ of the employers recognize the importance of mathematical competences in work relations and highly appreciate people who understand mathematics and can distinguish mathematical correlations in different research projects and activities.

Students were also asked a similar question about this issue: "Do you agree that people who understand mathematics well are highly appreciated by the employers?”

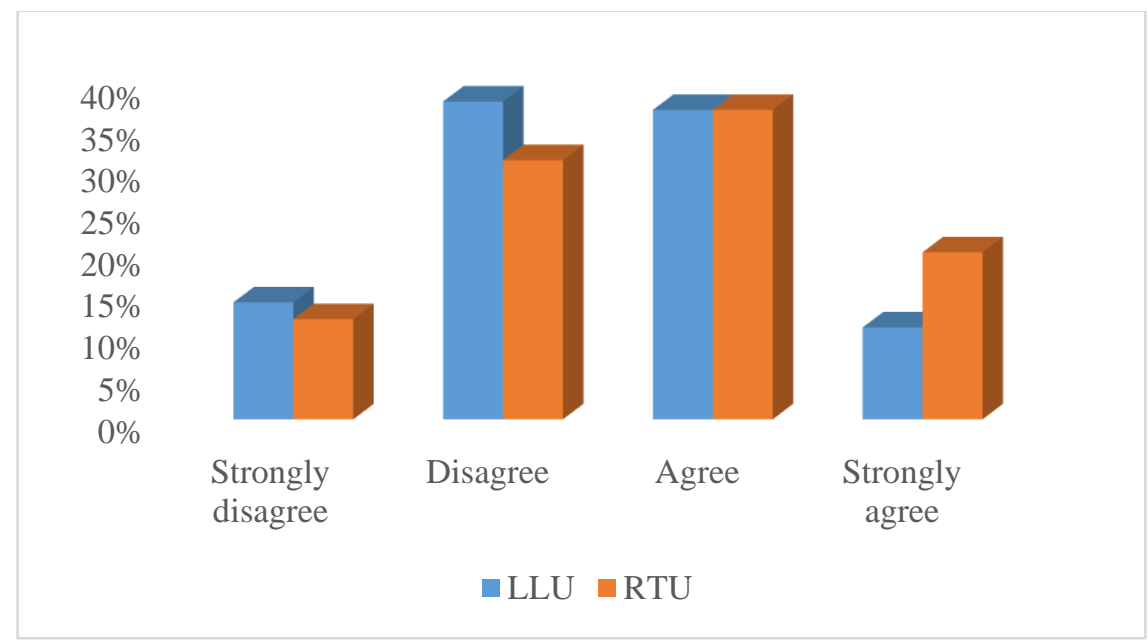

Picture 6. Do you agree that people who understand mathematics well are highly appreciated by the employers?

When observing students' answers (see Picture 6), one can see that $57 \%$ of RTU and $47 \%$ of LUA respondents strongly agree or agree to this statement, $56 \%$ disagree or have not thought about this question yet. Thus on average $44 \%$ of the respondents believe that mathematical skills are not significant enough to influence the attitude of the employer. Here we can notice relevant contradictions with the answers given by employers. Therefore, it would be necessary to give students more opportunities to take part in seminars, conferences and events with employers as lecturers or hosts. Thus students would gradually change their viewpoints and as a result, they would desire to focus more on exact courses, especially mathematics.

\section{CONCLUSIONS}

On the basis of study results derived from the analysis of the questioner (with 591 respondents `answer) it can be concluded that in general students appreciate the mathematical knowledge and skills gained at university. They use them for a successful start at the labour market, for coping with various situations and for problem solving. On average 50\%$60 \%$ of respondents highly appreciate the mathematical knowledge and understand its role in the development of a wellrounded personality and career.

Comparing respondents`answers from both universities - Riga Technical University and Latvia University of Agriculture - it can be concluded that the results do not differ significantly.

Analysis of the results among the clusters of specialties depicts that highest appreciation of mathematical competences and their use is expressed by the students of electronics and energy ( $70 \%$ on average). They have been able to precisely point out the areas in their specialty where the mathematical knowledge obtained at university is crucial. They also stress that mathematical thinking that has been established at university and is still developing is a worthy "foundation stone" for their future career. Students connected with the specialties of Economics also evaluate these competences rather high ( $68 \%$ on average), whereas the lowest evaluations for these competences is given by respondents whose specialties are computer management and information technologies ( $43 \%$ on average). Results of the study show that despite the fact that employers constantly stress the significance of the mathematical skills, $43 \%$ of RTU and $52 \%$ LUA respondents disagree with the statement that the people who understand mathematics well are better appreciated by employers.

The author of the study specifies that only the assessment method was used in this study, and the results are based on the beliefs and statements of the respondents. 


\section{ACKNOWLEDGEMENTS}

The author expresses gratitude to the researcher of the Latvia University of Agriculture Anna Vintere for cooperation and support in conducting a student survey.

\section{REFERENCES}

1. British Academy. 2012. Society Counts: Quantitative Skills in the Social Sciences (A Position Paper), pp. 1-12. London.

2. Burghes, D. 2011. International comparative study in mathematics teacher training. London.

3. Gainsburg, J. 2005. School mathematics in work and life: what we know and how we can learn more. Technology in Society, Vol. 27, Iss. 1, pp. 1-22. https://doi.org/10.1016/j.techsoc.2004.10.007

4. Hodgen, J., Marks, R. 2013. The Employment Equation: Why our young people need more maths for today's jobs. London

5. Norris, E. 2012. Solving the maths problem: international perspectives on mathematics education. London.

6. Porkess, R. 2012. The Future of Statistics in Schools and Colleges. London.

7. Silius, K., Pohjolainen, S., Kangas, J., Miilumaki, T. 2011. What can be done to bridge the competency gap between uppersecondary school and university mathematics? In Global Engineering Education Conference (EDUCON), pp. 428-436. https://doi.org/10.1109/EDUCON.2011.5773172

8. Vorderman, C., Porkess, R., Budd, C., Dunne, R., Rahman-hart, P. 2011. A world-class mathematics education for all our young people. London.

9. ACME. 2011. Mathematical Needs. Mathematics in the work place and in Higher Education. London. Available at http://www.acme-uk.org/media/7624/acme theme_a final\%20(2).pdf (Accessed on 10/10/2017).

10. Fatima, R., 2012. Role of Mathematics in the Development of Society Available at http://www.ncert.nic.in/pdf files/Final-ArticleRole\%20of\%20Mathematics\%20in\%20the\%20Development\%20ofSociety-NCER-.pdf (Accessed on 15/10/2017). 